\title{
Natureza e frequência dos erros na actividade de Medicina Geral e Familiar Geral num ACES - Estudo descritivo
}

Ana Maria Sequeira, ${ }^{*}$ Luís Martins, ${ }^{* *}$ Victor Hugo Pereira***

\section{RESUMO}

Objectivo: Conhecer a situação actual, respeitante a potenciais erros que possam ocorrer, ou a erros que ocorrem na actividade de medicina geral e familiar, num Agrupamento de Centros de Saúde (ACES) que presta cuidados de saúde primários, evidenciando a tipologia do erro e identificando as zonas de risco na trajectória do utente.

Métodos: Estudo descritivo, tendo como referência o estudo «Primary Care International Study of Medical Errors» (PCISME), de 2001, dirigido pelo Robert Graham Center of the American Academy of Family Physicians, o qual convidou investigadores de seis países (Austrália, Canadá, Holanda, Nova Zelândia, Reino Unido e Estados Unidos) e que define erro como «qualquer coisa que se identifica como errada, e que não deve voltar a ocorrer».

Resultados: Da amostra seleccionada, 20 médicos com a especialidade de medicina geral e familiar, 8 reportaram um total de 40 erros, os quais foram classificados de acordo com os níveis da tabela de classificação que emanou do estudo PCISME. Os níveis de classificação são: «erros no atendimento administrativo» 47,50\%; «erros com exames exploratórios» $25,00 \%$; «erros com tratamentos» 5,00\%; «erros de comunicação» 15,00\%; «erros de conhecimentos e de competências» 5,00\%; «outros erros» $2,50 \%$.

Conclusões: Os erros relatados pelos médicos com a especialidade de medicina geral e familiar neste estudo podem ser enquadrados nas tipologias internacionalmente estudadas e relatadas pelos médicos, no início desta década, para estudo internacional PCISME, que desde então tem sido base para diversos estudos a nível internacional sobre a problemática da segurança do doente nos cuidados de saúde primários.

Palavras-chave: Segurança; Atenção Primária à Saúde; Médico de Família.

\section{INTRODUÇÃO}

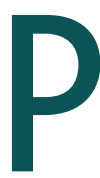

assaram dez anos sobre a publicação do relatório do Instituto de Medicina, em 1999, com o título «To err is Human -Building a safer health system», ${ }^{1}$ que foi o primeiro de uma série de relatórios do projecto sobre a Qualidade dos Cuidados de

* Mestre em Gestão das Organizações de Saúde, Responsável da Unidade de Apoio à Gestão do ACES VI - Loures.

** Coordenador do Mestrado em Gestão de Serviços de Saúde do ISCTE - Instituto Universitário de Lisboa, Departamento de Ciências de Gestão.

*** Professor convidado pelo ISCTE para o Mestrado de Gestão de Serviços de Saúde.
Saúde nos Estados Unidos, e que afirmava «Health care is not safer has it should be. A substancial body of evidence points to medical errors as a leading cause of death and injury», ${ }^{1}$ para de seguida apontar que 44.000 a 98.000 pessoas morriam por ano nos hospitais americanos devido a erros médicos que podiam ser prevenidos.

O dano causado aos doentes pelo sector da saúde tornou-se um fardo pesado na sociedade e, ao tomar consciência desta realidade, diversos países uniram os seus esforços no sentido de tomar medidas para solu- 
cionar o problema da segurança dos doentes nos cuidados de saúde, diminuindo a ocorrência de erros. Podem destacar-se as seguintes iniciativas institucionais: a criação da World Alliance for Patient Safety (WAPS), em Outubro de 2004, pela Organização Mundial de Saúde (OMS), a publicação da Declaração do Luxemburgo sobre a Segurança do Doente, ${ }^{2}$ em Abril de 2005, aquando da presidência luxemburguesa da União Europeia (EU) e a publicação pelo Comité de Ministros do Conselho de Europa da Recomendação $R E C(2006) 7$, $^{3}$ que reconhece, entre outras, a necessidade de promover a segurança do doente como um princípio fundamental dos sistemas de saúde dos Estados Membros e a aplicabilidade dos princípios da segurança do doente a todos os níveis de cuidados de saúde, desde a promoção da saúde ao tratamento da doença.

As medidas tomadas ainda não possibilitaram solucionar totalmente este problema, como evidencia o relatório Health in Portugal 2007, ${ }^{4}$ onde é referido que, no Reino Unido, um dos primeiros países a tomar medidas para aumentar a segurança do doente, a probabilidade de os utentes sofrerem um incidente no contacto com os serviços de saúde ainda se mantêm nos $10 \%$.

\section{Os Cuidados de Saúde Primários}

O progresso da medicina tem vindo a tornar os Cuidados de Saúde Primários (CSP) mais complexos. ${ }^{5}$ As áreas de intervenção que eram normalmente pertencentes aos cuidados de saúde secundários/hospitalares passaram para os CSP. As altas hospitalares precoces são agora a norma. A prescrição de medicamentos potencialmente perigosos tornou-se usual, assim como o acompanhamento de doentes com múltiplas patologias, normalmente idosos. Sobre a prescrição de medicamentos, Mara Guerreiro e colega ${ }^{6}$ referem que «uma meta-análise de estudos observacionais ... indicou que a prevalência de admissões hospitalares devido a morbilidade evitável relacionada com medicamentos (MERM) pode ser comparável, em países industrializados, às hospitalizações por cancro e enfarte do miocárdio».

Embora seja nos CSP que maioritariamente se dá o primeiro contacto do utente com os cuidados de saúde, a literatura sobre a segurança do doente não é tão variada, nem os estudos são tão comuns, como se poderia antever, talvez porque seja mais difícil estudar os erros, uma vez que têm lugar em vários locais, envolvem muitas consultas, presenciais, por telefone ou por e-mail, envolvendo ainda interacções com outros prestadores de saúde, estimando-se que «ao longo da sua carreira profissional um médico realizará mais de 100.000 consultas». ${ }^{7}$

Este estudo, ao abordar da segurança do doente nos CSP, pretende apenas pôr em evidência uma vertente da prestação de cuidados de saúde que, no ano de 2007, em Portugal, foi responsável por 28.989 .906 consultas em regime de ambulatório, envolvendo $26.704^{8}$ profissionais de diferentes áreas de actuação e que actualmente passa pelo «maior e mais profundo processo de redesenho organizacional da história do Serviço Nacional de Saúde - SNS».9

\section{O Erro}

A abordagem do erro pode ser efectuada por duas perspectivas distintas, a perspectiva individual e a perspectiva do sistema ou da organização. Na perspectiva individual é feita uma abordagem que se focaliza apenas no profissional que está no final da cadeia da prestação de cuidados de saúde, no entanto todas as recomendações das instituições internacionais vão no sentido de se procurar as causas do erro no sistema como um todo, procurando-se a solução para os erros que ocorrem nos mecanismos de segurança e na própria organização.

"A abordagem (do erro humano) no sistema presume que os erros e os acidentes são o resultado de uma longa cadeia de causas, uma sequência de falhas, latentes e activas que se alinham, provocando dano nos doentes (Reason 1990)» citado por Luís Martins, ${ }^{10}$ podendo definir-se falhas activas como «os erros e violações cometidas pelos que estão em contacto directo com a interface homem sistema», ${ }^{11} \mathrm{e}$ falhas latentes como "as acções tomadas nos escalões mais a montante da organização e do sistema». ${ }^{12}$

Recorrendo ao modelo do queijo suíço (Figura 1), verifica-se que em todas as organizações existem os dois tipos de falhas. A inexistência na organização de mecanismos para detectar ou controlar as falhas dá origem a acontecimentos fora de controlo, que podem levar à ocorrência de erros ou quase erros.

As formas que os erros podem assumir são lapsos ou enganos, existindo ainda a violação, que, segundo José 


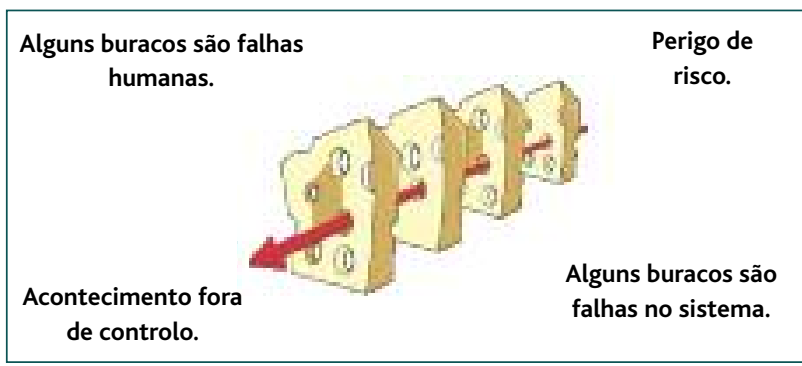

Figura 1. O modelo do queijo suíço.

Fragata e Luís Martins, «implica uma escolha e essa éa escolha deliberada de um comportamento que não éo standard e que viola as regras normais de actuação». ${ }^{13}$

\section{Os Sistemas de Reporte}

A legislação da UE e as orientações internacionais da OMS aconselham a criação e manutenção de sistemas de reporte de erros, que se focalizem na aprendizagem do erro e não na punição dos intervenientes, geridos por Agências Nacionais criadas para acompanhar a segurança do doente. São exemplos de Agências Nacionais, a Danish Society for Patient Safety, na Dinamarca, a Australian Patient Safety Foundation, na Austrália, a Canadian Patient Safety Foundation, no Canadá e ainda a National Patient Safety Agency no Reino Unido, entre outras.

A análise, catalogação e inscrição dos reportes obtidos em bases de dados nacionais é essencial para a obtenção de conhecimento. Este é posteriormente difundido com a publicação de normas, manuais de suporte à decisão clínica, campanhas de sensibilização aos profissionais entre outras acções. Deste modo as Agências Nacionais dão o seu contributo para a melhoria contínua no atendimento aos utentes, para a segurança dos cuidados de saúde, informando, apoiando e influenciando as organizações e os profissionais que trabalham no sector da saúde.

A criação de dezenas de Agências especializadas nos países que aderiram a este desafio global colocou um novo problema relacionado com a uniformização da classificação dos conceitos sobre a segurança do doente, uma vez que a proliferação de conceitos impediu avanços globais na segurança do doente, criando uma barreira significativa ao desenvolvimento de estratégias globais.
Tentando solucionar este problema foi criado um grupo internacional de profissionais para desenvolver a Classificação Internacional para a Segurança do Doente (CISD) - 2009, ${ }^{14}$ onde estão contidos os 48 termos preferenciais e definições de conceitos-chave. Ainda é um quadro conceptual, estando a WAPS a trabalhar em conjunto com a OMS, Departamento de Sistemas de Informação em Saúde, para transformar o quadro conceptual numa verdadeira classificação.

\section{MÉTODOS}

Na tentativa de conhecer a situação actual, respeitante a potenciais erros que possam ocorrer, ou a erros que ocorreram na actividade de medicina geral e familiar, num Agrupamento de Centros de Saúde (ACES), que presta cuidados de saúde primários no período compreendido entre 1 de Setembro e 23 Dezembro de 2009, evidenciando a tipologia do erro e identificando zonas de risco na trajectória do utente, foi efectuado um estudo descritivo, com o objectivo de responder à questão QUAL A NATUREZA E A FREQUÊNCIA DOS ERROS NA ACTIVIDADE DE MEDICINA GERAL E FAMILIAR GERAL NUM ACES.

Numa fase posterior, os dados obtidos foram comparados com os dados publicados no estudo Primary Care International Study of Medical Errors (PCISME, $)^{15}$ realizado no ano de 2001 pelo Robert Graham Center of the American Academy of Family Physicians, com seis países participantes: Austrália, ${ }^{16}$ Canadá, ${ }^{17}$ Holanda, Nova Zelândia, ${ }^{18}$ Reino Unido e Estados Unidos. ${ }^{19}$ Este teve como objectivo desenvolver a taxonomia internacional de erros nos cuidados de saúde primários.

\section{Desenho da Investigação}

O desenho da investigação seguiu os pressupostos do estudo PCISME adoptando-se, sempre que possível, a metodologia utilizada e o questionário para recolha de dados.

A cada médico participante era solicitado o reporte anónimo e confidencial, mínimo, de 10 erros detectados durante o seu horário de trabalho, reportado ao período compreendido entre 1 de Setembro e 23 de Dezembro.

Era ainda obrigatório para o médico efectuar um horário mínimo de 20 horas de consulta semanais e utilizar, diariamente, programas informáticos. 


\section{Participantes}

De uma população de 110 médicos da especialidade de medicina geral e familiar pertencentes ao ACES, em 1 de Setembro de 2009, foi recolhida uma amostra não aleatória por conveniência, de 20 médicos com a especialidade de medicina geral e familiar, pertencentes a Unidades de Saúde Familiares (USF) e a Unidades de Cuidados de Saúde Personalizados (UCSP).

\section{Definição de Erro}

A definição de erro utilizada foi a constante do estudo PCISME:20

«Erros são acontecimentos resultantes da prática diária que permitem concluir que houve uma ameaça para o bem-estar dos utentes e que devem ser evitados. Estes acontecimentos afectam ou podem afectar a qualidade dos cuidados prestados aos utentes.

Os erros podem ser pequenos ou grandes, administrativos ou clínicos, acções tomadas ou omissões, podendo não se identificar os seus efeitos. Os erros são, neste estudo, qualquer coisa que se identifica como errada, e que não deve voltar a ocorrer».

\section{Procedimentos e instrumento de recolha de dados}

Os médicos participantes responderam a um pré-questionário que se encontrava junto dos questionários de reporte de erros, do qual constavam, entre outras, as seguintes questões: data de início e de fim do reporte e número utentes inscritos na lista do médico.

Foram fornecidos a cada médico participante 10 questionários de reporte de erros (Quadro I), envelopados, previamente identificados com um número de ordem distintivo de forma a que as respostas de cada participante não fossem afectadas na sua confidencialidade, quer do respondente quer dos factos que reporta. Sempre que um médico na sua actividade diária detectava um erro, preenchia o questionário e remetia-o à investigadora, que não conhecia os números afectos a cada médico.

O questionário de reporte de erros observados é o mesmo que o utilizado no estudo PCISME, com as necessárias adaptações à língua portuguesa. Houve um teste-piloto do questionário de reporte de erros, que foi validado por seis médicos da especialidade de medicina geral e familiar, não participantes no estudo.

Como adaptação à realidade organizacional do ACES, introduziram-se duas novas alíneas no questio- nário, Serviços de Atendimento Permanente (SAP) / Centro de Atendimento e Tratamentos Urgentes (CATUS) e Sala de Enfermagem, ao ponto «l) Onde é que aconteceu o erro?» e foi suprimida a referência a cirurgia, uma vez que na estrutura organizacional Portuguesa os CSP estão separados dos Serviços Hospitalares.

\section{LIMITAÇÕES AO ESTUDO}

Este estudo foi preparado, acordado e implementado a partir de finais de 2008, no entanto o trabalho de campo só se iniciou no início de Setembro de 2009, depois da validação do pré-questionário por cada médico participante.

É limitação ao estudo o facto de apenas $40 \%$ da amostra seleccionada de médicos (8 em 20) terem entregue questionários de reporte de erros detectados na actividade diária.

Ocorreu ainda a entrega de questionários de reporte de erros que não puderam ser aceites pois o médico não preencheu todos os campos, nomeadamente o da idade e sexo dos utentes, e o anonimato dos questionários inviabiliza a possibilidade de contacto com o médico, no sentido de completar os mesmos.

Foi também limitação ao estudo o facto de 12 médicos não terem entregue em tempo útil nenhum questionário.

\section{RESULTADOS}

Os médicos respondentes foram 8. Nem todos os médicos se mostraram sensíveis à necessidade de serem efectuados este tipo de estudos.

Os reportes recebidos foram previamente analisados pela Presidente do Conselho Clínico do ACES, uma médica com a especialidade de medicina geral e familiar, uma vez que a investigadora não possuía conhecimento na área clínica. Seguidamente foram classificados numa das tipologias da tabela de classificação de erros do estudo PCISME e tratados informaticamente no programa informático Statistical Package for the Social Sciences (SPSS).

\section{Tipologia do erro}

Os dados obtidos através dos questionários de reporte de erros permitiram identificar 40 erros, que com excepção de uma das tipologias, a respeitante à factu- 
QUADRO I. Questionário de reporte de erros

\section{Questionário de reporte de erros}

\begin{tabular}{lc} 
Questão & Médico n. ${ }^{\circ}+$ \\
\hline
\end{tabular}

a) O problema está relacionado com um doente em particular

b) Se sim, até que ponto conhece o doente? (Lickert Scale)

c) Idade do doente.

d) Sexo do doente.

e) O doente é membro de um grupo étnico minoritário em Portugal?

f) O doente tem um problema de saúde complexo?

g) O doente tem um problema de saúde crónico?

h) O que aconteceu? Por favor considere o quê, onde e quem esteve envolvido.

i) Qual foi o resultado? Pense nas consequências actuais e potenciais.

j) O que pode ter contribuido para este erro? Por favor considere quaisquer circunstâncias especiais.

k) O que poderia ter prevenido o erro? Por favor considere o que deve mudar para evitar repetições.

l) Onde é que aconteceu o erro? (escolha todas as opções que se aplicam)

- Consultório

- No SAP/CATUS

- Sala de enfermagem

- Hospital

- Lares

- Domicílio do doente

- No contacto telefónico

- No Laboratório onde realizou exames

- Na Farmácia onde aviou o receituário

- Na RX onde realizou exames

m) Teve conhecimento de que outro doente fosse afectado por este erro?

SIM/NÃO

n) Se sim, como classificaria a gravidade deste erro? (Lickert Scale)

o) Com que frequência ocorre este erro na sua actividade?

Escolha

- $1 .^{a}$ vez

- Raramente (1 a 2 vezes por ano)

- Às vezes (3 a 11 vezes por ano)

- Frequentemente (mais de 1 vez por mês)

p) Outros comentários

Texto livre

ração ou pagamento, podem ser enquadrados nas tipologias internacionalmente estudadas (Quadro II).

Encontram-se Erros Processuais que têm a ver, entre outros, com Erros no Atendimento Administrativo. Este tipo de erros indica que ainda se cometem omissões, trocas de dados relevantes para o normal funcionamento de um serviço de saúde e que têm de ser minorados ou eliminados, quer pela formação interna dos profissionais, quer pela utilização de métodos informáticos que possam, através de informação redun- dante, permitir detectar as falhas e corrigi-las em tempo útil (Quadro II).

Foram relatados 8 erros na manutenção de um ambiente físico seguro, o que pela sua dimensão merece um comentário e uma análise mais aprofundada.

A realidade dos ACES existe apenas há alguns meses. Esta evolução do sistema de CSP levou a novos desenhos organizacionais, interdependências, dependências hierarquizadas, novas formas de municionamento logístico dos serviços de saúde, embora sem a dota- 
Tipo de erros

1. Erros processuais

1.1 Erros no Atendimento Administrativo

1.1.1. Erros de Arquivamento

1.1.2. Erros de Preenchimento Incompleto

1.1.3. Percurso do doente (no sistema de saúde)

1.1.4. Erros na gestão de mensagens

1.1.5.Erros de Marcação

1.1.6. Erros na manutenção de um ambiente fisico seguro

1.2. Erros com Exames Exploratórios

1.2.1. Laboratoriais

1.2.2. Exames de imagio1ogia

1.2.3. Erros no processamento de outros exames exploratórios

1.3. Erros com Tratamentos

1.3.1. Erros com medicação

1.3.2. Erros noutros tratamentos

1.4. Erros de Comunicação

1.4.1. Comunicação com os utentes

1.4.2. Comunicação com outros profissionais (não-clínico)

1.4.3. Comunicação com outros médicos

1.4.4. Erros de comunicação entre a equipa de saúde

\subsection{Erros com Pagamentos}

1.5.1. Erros no processamento de pedidos de seguradoras

1.5.2. Erros em pagamentos electrónicos

1.5.3. Pagamentos indevidos por serviços não efectuados

1.6. Erros na gestão dos profissionais de saúde

1.6.1. Ausências não preenchidas

1.6.2. Procedimentos de encaminhamento disfuncionais

1.6.3. Erros no escalar de funcionários extra-horário

2. Erros de conhecimentos e de competências

2.1. Execução de uma tarefa clínica

2.1.1. Pessoal não clínico tomou a decisão errada

2.1.2. Não foi cumprido o procedimnto padronizado

2.1.3. Verificou- se falta de experiência ou de perícia face a dado procedimento clínico

\subsection{Diagnóstico errado}

2.2.1. Erros de diagnóstico da enfermeira

2.2.2. Atrasos no diagnóstico

2.2.3. Diagnósticos errados ou atrasados devido a má interpretação de exames exploratórios

2.2.3. Diagnósticos errados ou atrasados devido a má interpretação da observação clinica

2.2.5. Diagnóstico errado por parte de um farmacêutico

2.2.5. Diagnóstico errado por médico hospitalar

\subsection{Decisão de tratamento errada com diagnóstico correcto}

2.3.1. Decisão de tratamento errada influenciada pelas preferências do utente

2.3.2. Decisão de tratamento errada por parte do médico

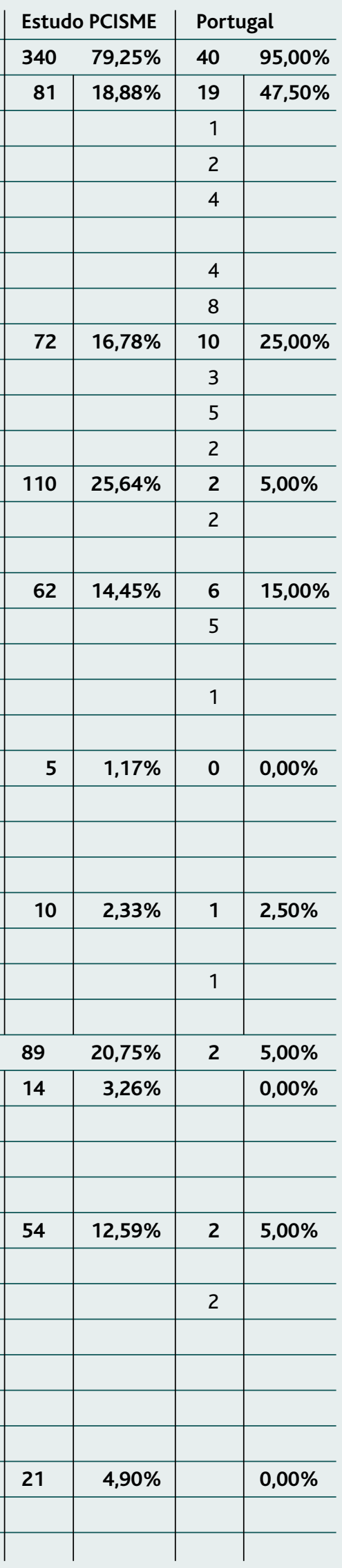




\begin{tabular}{|c|c|c|}
\hline Local & $\begin{array}{l}\text { Estudo } \\
\text { PSCISME } \\
n=341\end{array}$ & $\begin{array}{l}\text { Portugal } \\
n=40\end{array}$ \\
\hline Consultório & $64,30 \%$ & $72,50 \%$ \\
\hline No serviço de urgência & $3,50 \%$ & $2,50 \%$ \\
\hline Hospital & $12,50 \%$ & $7,50 \%$ \\
\hline Lares & $5,10 \%$ & $0,00 \%$ \\
\hline Domicílio do doente & $8,80 \%$ & $0,00 \%$ \\
\hline No contacto telefónico & $5,80 \%$ & $5,00 \%$ \\
\hline No laboratório onde realizou exames & $6,00 \%$ & $5,00 \%$ \\
\hline Na farmácia onde aviou o receituário & $4,20 \%$ & $2,50 \%$ \\
\hline No RX onde realizou exames & $2,30 \%$ & $7,50 \%$ \\
\hline Outros locais: & $7,40 \%$ & $20,00 \%$ \\
\hline No SAP/CATUS & & $2,50 \%$ \\
\hline Sala de enfermagem & & $2,50 \%$ \\
\hline Atendimento administrativo & & $15 \%$ \\
\hline
\end{tabular}

ção em recursos humanos necessários para colocar a máquina em «velocidade de cruzeiro». Realmente esta Reforma que vem alargar a base, pela inclusão de mais pessoas, abrangidas no SNS pelos CSP, é inovadora e a aprendizagem que tal obriga é constante, pelo que não seria possível ter previsto todas as necessidades em termos de formação, informação, número de profissionais e a sua distribuição na rede de CSP, o que leva a constantes ajustamentos para adequar o desenho organizacional à realidade que se lhe vai deparando.

Os 10 Erros com Exames Exploratórios podem revelar não só desperdício de meios, uma vez que estes exames são pedidos ao exterior, como também levar a atrasos nos diagnósticos e consequentes atrasos nas terapêuticas, com possibilidade de danos à saúde e bem-estar dos doentes, pois é a segurança do doente e a sua saúde a primeira preocupação.

Acresce que, para além dos aspectos fundamentais atrás enunciados, o SNS terá de alocar mais recursos em consultas e outros exames para poder validar com propriedade os diagnósticos correctos através de exames adequados. Há pois aqui um custo do ponto de vista do SNS perfeitamente identificável, que corresponde ao custo de exames efectuados erroneamente.

Em Erros com Tratamentos foram relatados 2 erros de medicação. Este tipo de erros é comum nas organiza- ções de saúde, sendo as suas causas múltiplas: vão desde má inserção de dados no sistema a trocas de identidades de utentes, troca de nome de medicamentos, incorrecta interpretação das receitas nas farmácias, insuficiente prescrição por parte do médico, entre outras causas e só a atenção constante e sistemas redundantes onde o próprio utente tem também um papel fundamental podem auxiliar todos os profissionais e doentes a evitar estes erros. O erro na medicação é sempre gravoso, embora, consoante o medicamento, a toma, a ausência, ou aparecimento de efeitos secundários, conduzam a estados de saúde perigosos, que possam causar dano ao doente.

Nos Erros de Comunicação, no que respeita à comunicação entre médicos e utentes, foram relatados 5 . Quando ocorre este tipo de incidentes, isso revela que há um grande distanciamento cultural entre o profissional de saúde e o doente, que muitas vezes não entende o que o médico lhe explica, o que leva a gravosos riscos, porque o utente fará aquilo que entendeu erroneamente e não aquilo que deveria fazer para defender a sua saúde.

Esta situação só melhorará pelo esforço que o profissional de saúde deve fazer no sentido de assegurar que o utente entendeu a prescrição clínica, se necessário fazendo-o repetir por palavras suas o que o médico lhe acabou de explicar.

No entanto, mesmo entre profissionais de saúde, entre médicos, a comunicação não é fluida e isenta de más interpretações técnicas, tendo sido relatado 1 erro, justamente por má interpretação ou comunicação entre dois médicos. Aqui o esforço tenderá a ser de poder comunicar entre colegas de uma forma mais próxima e de igualmente haver o hábito de se solicitar «feed-back» para que o emissor se certifique de que o receptor entendeu perfeitamente o que lhe estava a ser pedido ou informado.

Na Gestão dos Profissionais de Saúde, nos procedimentos de encaminhamento disfuncionais, foi reportado 1 erro, que diz respeito à forma automática de marcação de primeiras consultas de especialidade clínica hospitalar através do sistema informático Alert $\mathrm{P} 1$ e que mostrou a possibilidade de, em alguns casos, o Sistema de Marcação entre Centros de Saúde e Hospitais não ser fiável. O encaminhamento acabou por não se fazer, apesar do doente ter sintomatologia grave, tendo havi- 
do necessidade de intervenção do clínico do ACES para contactar o hospital no sentido de que o seu doente fosse incluído em consulta de especialidade, mas tal só ocorreu 6 meses depois do processo automático ter sido utilizado e em último recurso, para não trazer maiores danos ao utente.

O sistema informático Alert P1 tem vindo a melhorar mas necessita de sistemas redundantes que permitam detectar, automaticamente, tudo o que revela demoras excessivas.

Finalmente foram reportados 2 erros de Conhecimento e de Competências, no que respeita a diagnósticos errados ou atrasados. $\mathrm{O}$ atraso no diagnóstico pode em determinadas patologias redundar num grave dano para o utente. As causas vão desde a má informação do utente sobre as queixas que apresenta e que não procura um médico, demora na consulta, nos meios auxiliares de diagnóstico e na consulta subsequente para confirmação de diagnóstico e delineamento das terapêuticas a efectivar.

Em qualquer dos casos, a saúde do doente é posta em causa e os custos para o sistema de saúde poderão ser muito maiores dado que intervir mais tarde, em regra, é sempre mais caro pela maior agressividade dos tratamento a efectuar, mais dias de internamento, se for o caso, e possivelmente com os custos futuros associados à doença. Tudo isto se não tiver levado entretanto ao falecimento do próprio utente.

De salientar que os médicos que relataram os 40 erros, também efectuaram as respectivas sugestões para evitar novamente a ocorrência do erro.

Comparando os erros relatados no PCISME e aqueles encontrados no estudo realizado em Portugal, no presente estudo podemos retirar que os erros administrativos são $252 \%$ mais elevados em Portugal, o que pode revelar o enorme caminho que ainda é preciso percorrer no sentido de optimizar os processos, tornando-os fiáveis.

Os incidentes relatados como os exames exploratórios são no estudo português $149 \%$ mais elevados, o que também indica que há um caminho de eficiência a trilhar no maior cuidado que o sistema tem que ter, no pedido de exames laboratoriais imunológicos e outros, bem como no cuidado que as organizações que fornecem esses serviços ao SNS terão que ter, para se assegurarem que os exames realizados foram os solicitados.
Nos erros relatados respeitantes aos tratamentos, os valores apresentados no estudo português são 19,5\% inferiores ao do PCISME. Este valor é lisonjeiro mas deve ser relativizado uma vez que a cultura dominante continua a ser o de não reportar erros deste tipo. Independentemente disso, é um valor francamente muito bom e que não pode ser ignorado.

Os erros de pagamentos ou facturação não foram reportados no estudo português por não ser uma preocupação clínica e daí a não resposta a este tipo de erros ter apenas a ver com aquilo que o clínico entende ser a sua missão dentro da organização. No PCISME este tipo de erros correspondeu a $1 \%$.

O erro na gestão dos profissionais de saúde é idêntico nos dois estudos, $2 \%$, o que de alguma forma baliza e identifica esta situação como sendo transversal nos CSP nos países em estudo.

$\mathrm{O}$ erro de Conhecimentos e de Competências, no estudo comparado, também é muito lisonjeiro para o caso português, dado que o valor encontrado é de apenas $24 \%$ dos valores apresentados no PCISME. Por questões metodológicas e de prudência, não desvalorizando os valores encontrados, a reserva que a investigadora faz é que tal pode dever-se à cultura mais enraizada na nossa sociedade de não relatar este tipo de incidentes.

\section{Zonas de Risco}

Recorrendo à metodologia do Health Care Failure Mode and Effect Critical Analysis (HFMEA), um instrumento interno de análise avaliativa do processo de prestação de cuidados de saúde, que possibilita a implementação de culturas de segurança e redução de erros, foi desenhado o fluxograma do processo (Figura 2), em que constam as várias etapas percorridas pelo utente, desde a sua entrada na instituição até à sua saída, evidenciando os profissionais envolvidos e os sistemas de informação.

Posteriormente, com base nos resultados obtidos pelo tratamento estatístico dos reportes, em particular a frequência com que ocorriam em cada etapa, foi conduzida uma análise das falhas e riscos de cada etapa do processo e atribuição de pontuação (Quadro IV). As falhas foram analisadas pelos efeitos (gravidade) e causas (grau de ocorrência e detecção). Para cada causa-efeito foi atribuído o Risk Priotity Number (RPN), calculado pela fórmula: $R P N=$ [gravidade $\mathrm{x}$ ocorrência $\mathrm{x}$ 


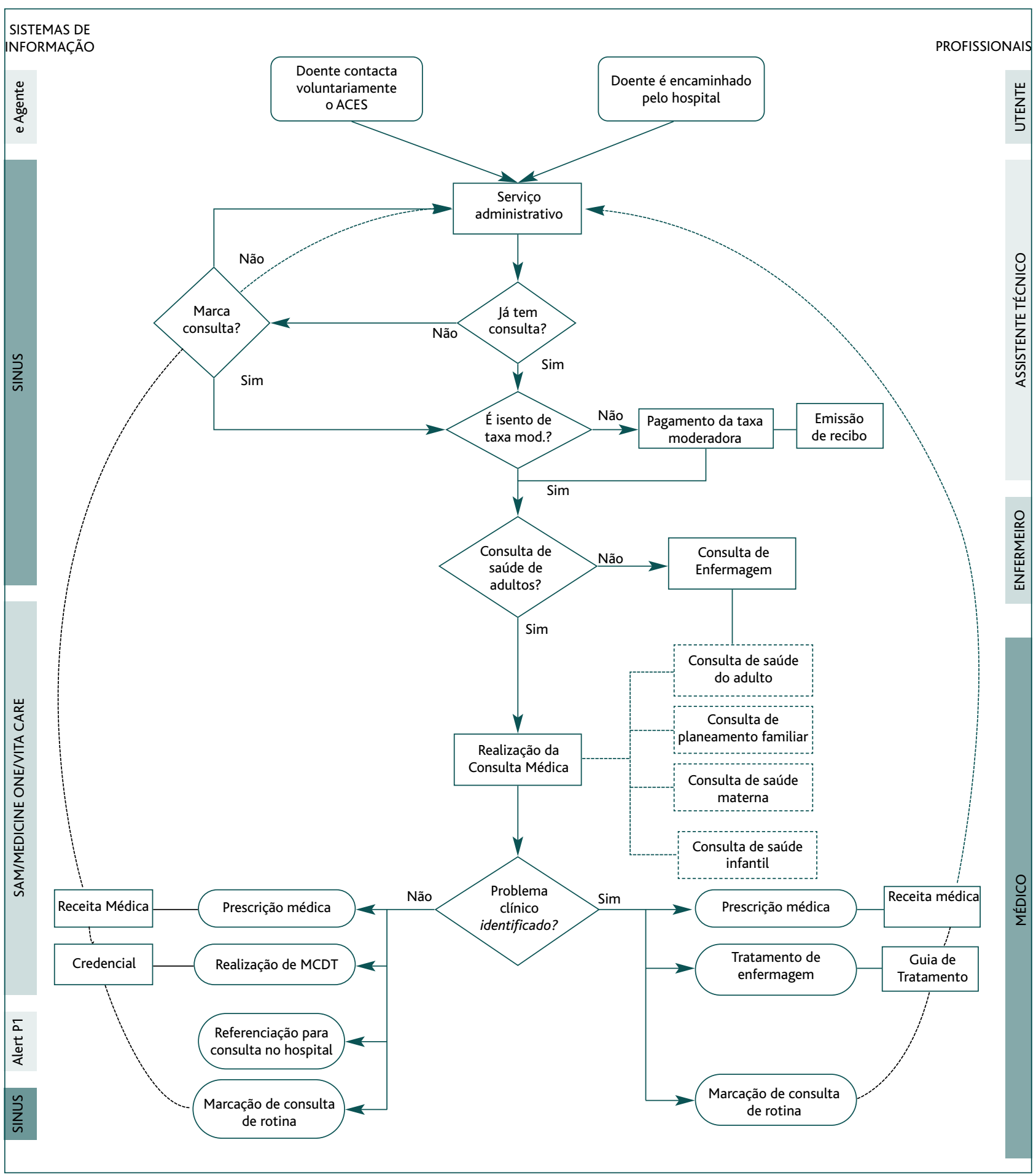

Figura 2. A trajectória do utente de Medicina Geral e Familiar num ACES. 


QUADRO IV. Risk Priority Number
\begin{tabular}{l|l|l|l} 
Grau & Gravidade & Ocorrência & Detecção \\
\hline 1 & Irrelevante & $\begin{array}{l}\text { Possibilidade remota } \\
\text { (1.a vez ou 1 a 2 vezes } \\
\text { por ano) }\end{array}$ & $\begin{array}{l}\text { Antes de chegar } \\
\text { ao doente }\end{array}$ \\
\hline 5 & $\begin{array}{l}\text { Incómodo perda } \\
\text { de performance }\end{array}$ & $\begin{array}{l}\text { Ocorre moderadamente } \\
\text { (3 a 11 vezes por ano) }\end{array}$ & $\begin{array}{l}\text { Probabilidade moderada } \\
\text { de não detectar }\end{array}$ \\
\hline 9 & Alta gravidade & $\begin{array}{l}\text { Ocorre frequêntemente } \\
\text { (mais de 1 vez por mês)* }\end{array}$ & Passa para o doente \\
\hline
\end{tabular}

*Valores constantes do questionário aplicado ao estudo.

detecção], cujo resultado, entre 1 e 729 , indica as zonas mais críticas da trajectória do utente de medicina geral e familiar num ACES (Quadro V).

\begin{tabular}{|c|c|c|c|c|c|c|c|c|}
\hline Etapas & Descrição & Falhas & Efeito & Grav. & Causa & Ocor. & Detec. & RPN \\
\hline 1 & $\begin{array}{l}\text { Marcação de } \\
\text { consultas }\end{array}$ & $\begin{array}{l}\text { Demora na } \\
\text { realização da } \\
\text { consulta em } \\
\text { virtude de listas } \\
\text { de utentes sem } \\
\text { médico ou falha } \\
\text { do funcionário }\end{array}$ & $\begin{array}{l}\text { Atraso no } \\
\text { processo }\end{array}$ & 5 & $\begin{array}{l}\text { Falta de médicos } \\
\text { e formação } \\
\text { específica }\end{array}$ & 6 & 6 & 180 \\
\hline 2 & $\begin{array}{l}\text { Actualização/ } \\
\text { /preenchimento } \\
\text { arquivo de dados } \\
\text { mal efectuado }\end{array}$ & $\begin{array}{l}\text { Demora na } \\
\text { realização da } \\
\text { consulta em } \\
\text { virtude de erros de } \\
\text { registo }\end{array}$ & $\begin{array}{l}\text { Sujeitar o doente a } \\
\text { demora na } \\
\text { realização da } \\
\text { consulta ou de } \\
\text { outros tratamentos }\end{array}$ & 5 & $\begin{array}{l}\text { Cansaço, } \\
\text { desconcentração }\end{array}$ & 6 & 6 & 180 \\
\hline 3 & $\begin{array}{l}\text { Má orientação dos } \\
\text { utentes no percurso } \\
\text { a efectuar }\end{array}$ & $\begin{array}{l}\text { Transtorno para os } \\
\text { utentes e demais } \\
\text { profissionais de } \\
\text { saúde }\end{array}$ & $\begin{array}{l}\text { Descontentamento } \\
\text { dos utentes e má } \\
\text { imagem } \\
\text { organizacional }\end{array}$ & 5 & $\begin{array}{l}\text { Recursos humanos } \\
\text { deficitários e } \\
\text { aplicações } \\
\text { informáticas } \\
\text { recentes }\end{array}$ & 7 & 6 & 210 \\
\hline 4 & $\begin{array}{l}\text { Manutenção de } \\
\text { um ambiente físico } \\
\text { seguro }\end{array}$ & $\begin{array}{l}\text { Problemas na } \\
\text { logística do ACES }\end{array}$ & $\begin{array}{l}\text { Atrasos no regular } \\
\text { funcionamento dos } \\
\text { serviços de saúde }\end{array}$ & 8 & $\begin{array}{l}\text { Reforma dos CSP } \\
\text { em curso }\end{array}$ & 9 & 9 & 648 \\
\hline 5 & Consulta médica & Diagnóstico errado & $\begin{array}{l}\text { Realização de nova } \\
\text { consulta }\end{array}$ & 8 & $\begin{array}{l}\text { Insuficiente } \\
\text { informação clínica } \\
\text { sobre o doente }\end{array}$ & 6 & 9 & 432 \\
\hline 6 & $\begin{array}{l}\text { Prescrição de } \\
\text { medicamentos }\end{array}$ & Prescrição errada & $\begin{array}{l}\text { Danos que podem } \\
\text { ser irreparáveis }\end{array}$ & 9 & $\begin{array}{l}\text { Insuficiente } \\
\text { informação sobre } \\
\text { as propriedades } \\
\text { farmacológicas }\end{array}$ & 7 & 9 & 567 \\
\hline 7 & $\begin{array}{l}\text { Pedido de exames } \\
\text { e análise dos } \\
\text { exames realizados }\end{array}$ & $\begin{array}{l}\text { Erro na identificação } \\
\text { do exame a solicitar } \\
\text { e estabelecimento } \\
\text { de diagnósticos } \\
\text { errados }\end{array}$ & $\begin{array}{l}\text { Sujeitar o doente a } \\
\text { mais testes e } \\
\text { demoras na } \\
\text { realização dos } \\
\text { exames }\end{array}$ & 9 & $\begin{array}{l}\text { Cansaço. } \\
\text { Desconcentração } \\
\text { e falta de } \\
\text { experiência em } \\
\text { casos mais difíceis }\end{array}$ & 9 & 7 & 567 \\
\hline 8 & $\begin{array}{l}\text { Comunicação ao } \\
\text { utente do } \\
\text { diagnóstico e } \\
\text { tratamento }\end{array}$ & $\begin{array}{l}\text { Danos irreparáveis } \\
\text { por incumprimento } \\
\text { da terapêutica. }\end{array}$ & $\begin{array}{l}\text { Relação médico- } \\
\text {-doente } \\
\text { insatisfatórias }\end{array}$ & 8 & $\begin{array}{l}\text { Conhecimento dos } \\
\text { procedimentos } \\
\text { mas falha nas } \\
\text { acções }\end{array}$ & 7 & 8 & 504 \\
\hline 9 & $\begin{array}{l}\text { Comunicação com } \\
\text { outras entidades e } \\
\text { profissionais de } \\
\text { saúde }\end{array}$ & $\begin{array}{l}\text { Forma inadequada } \\
\text { de proceder a esta } \\
\text { comunicação }\end{array}$ & Atraso no processo & 7 & $\begin{array}{l}\text { Problemas } \\
\text { estruturais. Erros } \\
\text { dos sistemas } \\
\text { informáticos }\end{array}$ & 3 & 9 & 189 \\
\hline
\end{tabular}




\section{CONCLUSÕES}

"As grandes organizações preservam os seus valores fundamentais e os seus propósitos ao mesmo tempo que delineiam estratégias e realizam práticas adaptáveis ao mundo em mudança. Esta combinação mágica de preservar o que é "core» e estimular o progresso»" têm de ser o motus de desenvolvimento das organizações de saúde públicas neste início conturbado do século XXI.

Um sistema de saúde em evolução tem de ser capaz de produzir satisfação nos utentes, orgulho na sociedade, confiança nas famílias, dando oportunidade aos profissionais que nele trabalham de uma carreira estimulante, desafiante e que possa motivá-los para estarem aptos aos desafios que todos os dias lhe são lançados.

«O facto da actividade da administração poder ser exercida por entidades privadas e entes públicos poderem ser regidos pelo direito privado» não deve ter por efeito «... uma fuga às garantias constitucionais dos cidadãos...». ${ }^{22}$ É nesse sentido que a reforma em curso, no que aos cuidados de saúde primários diz respeito, pode ser um factor de equidade na sociedade portuguesa, induzindo mais saúde na população, libertando os hospitais de uma procura excessiva, particularmente das urgências e nas consultas das doenças da sociedade actual relacionadas com falta de hábitos saudáveis de vida, criando cidadãos mais responsáveis na manutenção do seu capital saúde, o que levará a uma contenção do crescimento dos custos globais na área da saúde.

«Uma mudança na cultura em última análise depende da implementação de comportamentos individuais na organização que reforceme sejam consistentes com a nova cultura de valores», ${ }^{23}$ e estes decorrem duma reestruturação dos CSP que sejam realmente a porta de entrada do SNS, trazendo novas competências clínicas para junto das comunidades, duma forma descentralizada e em articulação com o poder local, com as escolas com as IPSS e demais forças vivas comunitárias.

Compete ao poder político democraticamente mandatado na nossa sociedade pelos portugueses, criar as condições para que os cuidados de saúde primários sejam um garante de uma população mais saudável, co-responsável na sua saúde e que possa gerar mais riqueza na economia, proporcionando maiores receitas ao Estado que desta forma pode investir estrategicamente no SNS.
Este estudo, embora focalizado apenas num ACES, pode ser extrapolável para outros ACES, uma vez que os erros encontrados não são atribuíveis a um fenómeno isolado mas antes decorrem de situações comuns no nosso sistema de saúde, das ferramentas que estão a ser disponibilizadas, particularmente as informáticas, bem como pelo tipo de população abrangida, uma vez que este ACES, sendo parte da região metropolitana de Lisboa, detém população urbana, população rural, população migrante e emigrante, população jovem e população idosa e os extractos socioeconómicos são os mais díspares.

"A prevenção dos erros pode considerar-se primária quando actuamos antes de este acontecer prevendo-o". ${ }^{24}$ Identificar os erros é pois a melhor forma de aumentar a eficácia das organizações, pelo que um trabalho como este, em que o reporte de erros é transversal à organização, proporciona informação útil, ponto de partida para tornar mais seguras as organizações sobretudo quando da saúde se trata.

Um erro reportado é sempre um ganho organizacional enorme na medida em que pode ser estudado para que não ocorra no futuro. Esta postura está ainda longe dos nossos hábitos quotidianos mas aos poucos tem vindo a impor-se e a prová-lo estão os 40 questionários obtidos para este trabalho. O número é exíguo para dar robustez as conclusões, no entanto não se afasta muito dos números relatados nos estudos internacionais.

O reporte de erros em Portugal, ainda que protegidos pelo sigilo e anonimato, não é ainda bem visto nas várias classes profissionais em que a saúde não é excepção.

«Ao contrário da abordagem clássica centrada no evitamento da falha, háautores que entendem a falha como um pré-requisito essencial para uma efectiva aprendizagem» (SITKIN 1992, citado por Luís Martins). ${ }^{25}$

«A performance ou eficácia organizacional é uma noção multidimensional», ${ }^{26} \mathrm{em}$ que factores culturais, a experiência técnica vivida pelos profissionais de saúde, a aprendizagem ao longo da vida, a educação para a saúde na comunidade, os extractos socioeconómicos de onde provêm, os utentes, a força da sociedade civil e a interacção entre as pessoas na comunidade, culminando no SNS, formatam a possibilidade de maior performance no ACES e no cumprimento integral das missões que lhe estão confiadas pela carta de missão: «Aos Directores Executivos coloca-se um grande desafio que 
é, sem dúvida, criar uma cultura que fomente o compromisso das pessoas com um projecto comum, uma cultura de administração pública que vise a prossecução do interesse público, no respeito pelos direitos e interesses legalmente protegidos dos cidadãos $\rangle^{27}$.

\section{REFERÊNCIAS BIBLIOGRÁFICAS}

1. Kohn LT, Corrigan JM, Donaldson MS. To Err Is Human: building a safer health system. Washington, DC: National Academy Press; 1999.

2. Luxembourg Declaration on Patient Safety. Patient Safety.-Making it Happen! - Luxembourg, 5 April 2005. Disponível em: http://ec.europa.eu/health/ph_overview/ Documents/ev_20050405_rd01_en.pdf [acedido em 23/12/2009].

3. Council of Europe Committee of Ministers. Recommendation $\operatorname{Rec}(2006) 7$ of the Committee of Ministers to member states on management of patient safety and prevention of adverse events in health care. disponível em: https://wcd.coe.int/wcd/ViewDoc.jsp?id=1005439 \&Site=CM [acedido em 23/12/2009].

4. Directorate-General of Health (Portugal). Health in Portugal. Portuguese Presidency of the Council of the European Union. Lisbon: Directorate-General of Health, Ministry of Health; 2007.

5. Wilson T, Rogers S. Reducing risk and promoting safety in primary care. In: van Zwanenberg T, Harrison J, editors. Clinical Governance in Primary Care. 2 nd ed. Oxon: Radcliffe Medical Press; 2009. p. 135-49.

6. Guerreiro M, Cantrill JA, Martins AP. Morbilidade evitável relacionada com medicamentos: validação de indicadores para cuidados primários em Portugal. Acta Med Port 2007 Mar-Abr; 20 (2): 107-29.

7. Bunting R, Benton J. Primary and ambulatory care. In: Carroll R, editor. Risk Management Handbook for Health Care Organization. 4th ed. Chicago: American Society for Healthcare Risk Management; 2004. p. 335-71.

8. Direcção-Geral da Saúde. Centros de Saúde e Hospitais, recursos e produção do SNS - Estatísticas 2007. Lisboa: Direcção-Geral da Saúde; 2007.

9. Observatório Português dos Sistemas de Saúde. Relatório da Primavera 2008: O Sistema de Saúde português: riscos e incertezas. Coimbra: Centro de Estudos e Investigação em Saúde da Universidade de Coimbra; 2008.

10. Fragata J, Martins L. Causas e mecanismos dos erros em medicina: anatomia do erro. In: Fragata J, Martins L, editores. O Erro em Medicina: perspectivas do indivíduo, da organização e da sociedade. Coimbra: Almedina; 2008. p. 41-80.

11. Fragata J, Martins L. Causas e mecanismos dos erros em medicina: anatomia do erro. In: Fragata J, Martins L, editores. O Erro em Medicina: perspectivas do indivíduo, da organização e da sociedade. Coimbra: Almedina; 2008. p. 41-80.

12. Fragata J, Martins L. Causas e mecanismos dos erros em medicina: anatomia do erro. In: Fragata J, Martins L, editores. O Erro em Medicina: perspectivas do indivíduo, da organização e da sociedade. Coimbra: Almedina; 2008. p. 41-80.

13. Fragata J, Martins L. Causas e mecanismos dos erros em medicina: anatomia do erro. In: Fragata J, Martins L, editores. O Erro em Medici- na: perspectivas do indivíduo, da organização e da sociedade. Coimbra: Almedina; 2008. p. 41-80.

14. Runciman W, Hibbert $P$, Thomson R, Van Der Schaaf $T$, Sherman $H$, Lewalle P. Towards an International Classification for Patient Safety: key concepts and terms. Int J Qual Health Care 2009 Feb; 21 (1): 18-26.

15. Makeham MA, Dovey SM, County M, Kidd MR. An international taxonomy for errors in general practice: a pilot study. Med J Aust 2002 Jul $15 ; 177(2)$ : 68-72.

16. Makeham MA, Dovey SM, County M, Kidd MR. An international taxonomy for errors in general practice: a pilot study. Med J Aust 2002 Jul $15 ; 177$ (2): 68-72.

17. Jacobs S, O'Beirne M, Derfiingher LP, Vlach L, Rosser W, Drummond N. Errors and adverse events in family medicine: developing and validating a Canadian taxonomy of errors. Can Fam Physician 2007 Feb; 53 (2): 270-6.

18. Tilyard M, Dovey S, Hall K. Avoiding and fixing medical errors in general practice: prevention strategies reported in the Linnaeus Collaboration's Primary Care International Study of Medical Errors. N Z Med J 2005 Jan 28; 118 (1208): U1264.

19. Woolf SH, Kuzel AJ, Dovey SM, Philips RL Jr. A string of mistakes: the importance of cascade analysis in describing, counting, and preventing medical errors. Ann Fam Med 2004 Jul-Aug; 2 (4): 317-26.

20. Makeham MA, Dovey SM, County M, Kidd MR. An international taxonomy for errors in general practice: a pilot study. Med J Aust 2002 Jul $15 ; 177$ (2): 68-72.

21. Collins J. Good to Great. New York: Harper Collins Publishers; 2001.

22. Simões J. Retrato político da saúde. Coimbra: Almedina; 2005.

23. Fragata J, Martins L. O erro nas diferentes especialidades médicas. In: Fragata J, Martins L, editores. O Erro em Medicina: perspectivas do indivíduo, da organização e da sociedade. Coimbra: Almedina; 2008. p. 81-105.

24. Fragata J, Martins L. Como evitar os erros em medicina. In: Fragata J, Martins L, editores. O Erro em Medicina: perspectivas do indivíduo, da organização e da sociedade. Coimbra: Almedina; 2008. p. 119- 121.

25. Martins L. O erro com periferia do sistema. In: Fragata J, Martins L, editores. O Erro em Medicina: perspectivas do indivíduo, da organização e da sociedade. Coimbra: Almedina; 2008. p. 147-211.

26. Martins L. O erro com periferia do sistema. In: Fragata J, Martins L, editores. O Erro em Medicina: perspectivas do indivíduo, da organização e da sociedade. Coimbra: Almedina; 2008. p. 147-211.

27. Carta de Missão dos Directores Executivos do ACES. Disponível em: https://www.mcsp.min-saude.pt [acedido em 23/12/2009].

\section{CONFLITOS DE INTERESSE}

Os autores declaram não possuir conflitos de interesse

\section{ENDEREÇO PARA CORRESPONDÊNCIA}

Instituto Superior de Ciências do Trabalho e da Empresa

Av. Forças Armadas, 1649-026 Lisboa

Recebido em 03/12/2010

Aceite para publicação em 26/12/2010 


\section{ABSTRACT}

\section{THE NATURE AND FREQUENCY OF THE ERROS IN THE BUSINESS OF GENERAL PRACTCE, IN A PRIMARY HEALTH CARE UNIT, IN PORTUGAL. THIS IS A DESCRIPTIVE STUDY}

Purpose of the Study: Understanding the current situation in relation to potential errors that may occur in general practice, in a Primary Health Care setting, in Portugal, with the purpose of demonstrating the type of errors and identifying risks in a patient's circuit within the unit.

Methodology: The method used for this study was descriptive, using as reference "Primary Care International Study of Medical Errors" (PCISME), 2001, directed by the Robert Graham Center of the American Academy of Family Physicians, who invited researchers from six countries to participate (Australia, Canada, Netherlands, New Zealand, United Kingdom and the United States). Error is defined as "anything that you identify as something wrong, to be avoided in the future".

Main Results Attained: From the sample made up of 20 General Practitioners, 8 of them reported a total of 40 errors, which were classified according to the assessment categories, which emerged from the PCISME study.

The levels of classification refers to "Errors in office administration" - 47,50\%; "Investigation errors" - 25,00\%; "Treatment errors" - 5,00\%; "Communication errors" - 15,00\%; "knowledge and skills errors" - 5,00\%; "Other errors" - 2,50\%.

Conclusions: The errors reported by Family Physicians in this study may be classified within those reported by physicians in the beginning of the present decade. All of these are referred in the international study PCISME, which has been the basis for several studies at international level, concerning the issue of patient safety in primary care.

Keywords: Safety; Primary Health Care; Family Physicians. 